\title{
Detection Thresholds of Falling Snow from Satellite-borne Active and Passive Sensors
}

\author{
Gail Skofronick-Jackson, NASA Goddard Space Flight Center, Code 612, Bldg. 33, Rm. \\ A416, Greenbelt, MD 20771 USA, 301-614-5720, Gail.S.Jackson@nasa.gov
}

Benjamin T. Johnson and S. Joseph Munchak

Precipitation, including rain and snow, is a critical part of the Earth's energy and hydrology cycles. Precipitation impacts latent heating profiles locally while global circulation patterns distribute precipitation and energy from the equator to the poles. For the hydrological cycle, falling snow is a primary contributor in northern latitudes during the winter seasons. Falling snow is the source of snow pack accumulations that provide fresh water resources for many communities in the world. Furthermore, falling snow impacts society by causing transportation disruptions during severe snow events. In order to collect information on the complete global precipitation cycle, both liquid and frozen precipitation must be collected.

The challenges of estimating falling snow from space still exist though progress is being made. These challenges include weak falling snow signatures with respect to background (surface, water vapor) signatures for passive sensors over land surfaces, unknowns about the spherical and non-spherical shapes of the snowflakes, their particle size distributions (PSDs) and how the assumptions about the unknowns impact observed brightness temperatures or radar reflectivities, differences in near surface snowfall and total column snow amounts, and limited ground truth to validate against. While these challenges remain, knowledge of their impact on expected retrieval results is an important key for understanding falling snow retrieval estimations.

Since falling snow from space is the next precipitation measurement challenge from space, information must be determined in order to guide retrieval algorithm development for these current and future missions. This information includes thresholds of detection for various sensor channel configurations, snow event system characteristics, snowflake particle assumptions, and surface types. For example, can a lake effect snow system with low $(\sim 2.5 \mathrm{~km})$ cloud tops having an ice water content (IWC) at the surface of $0.25 \mathrm{~g} \mathrm{~m}^{-3}$ and dendrite snowflakes be detected? If this information is known, we can focus retrieval efforts on detectable storms and concentrate advances on achievable results.

Here, the focus is to determine thresholds of detection for falling snow for various snow conditions over land and lake surfaces. The results rely on simulated Weather Research Forecasting (WRF) simulations of falling snow cases since simulations provide all the information to determine the measurements from space and the ground truth. Sensitivity analyses were performed to better ascertain the relationships between multifrequency microwave and millimeter-wave sensor observations and the falling snow/underlying field of view. In addition, thresholds of detection for various sensor channel configurations, snow event system characteristics, snowflake particle assumptions, and surface types were studied. Results will be presented for active radar at $\mathrm{Ku}, \mathrm{Ka}$, and $\mathrm{W}$-band and for passive radiometer channels from 10 to $183 \mathrm{GHz}$. 